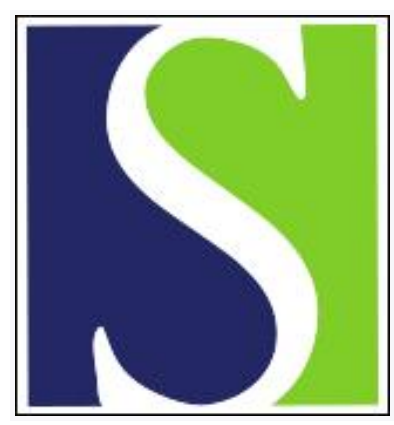

Scand J Work Environ Health 1986;12(4):355-358

https://doi.org/10.5271/sjweh.2129

Issue date: Aug 1986

Accuracy of measuring impedance in the hand-arm system. by Hempstock TI, O'Connor DE

This article in PubMed: www.ncbi.nlm.nih.gov/pubmed/3775323

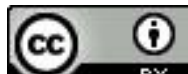




\title{
Accuracy of measuring impedance in the hand-arm system
}

\author{
by T Ian Hempstock, BSc, PhD, David E O'Connor, MSc' ${ }^{1}$
}

\begin{abstract}
HEMPSTOCK TI, O'CONNOR DE. Accuracy of measuring impedance in the hand-arm system. Scand $J$ Work Environ Health 12 (1986) 355-358. In an assessment of the accuracy with which impedance can be determined in the hand-arm system, two subjects were each tested six times at 28 frequencies between 10 and $800 \mathrm{~Hz}$. In addition the effect of wearing an air cushion glove was investigated, and an attempt was made to develop a simple model of the glove. The results showed agreement with other recently published data for impedance in the hand-arm system at frequencies above about $25 \mathrm{~Hz}$ but not below. The mean values of the impedance for a single subject had standard errors of about $10 \%$. When the subjects wore an air cushion glove, there was only a small change in impedance, and consequently in the total amount of energy dissipated in the hand-arm system. A simple mass-spring damper model of the glove predicted that the attenuation provided by the glove was minimal, except at the highest frequencies.
\end{abstract}

Key terms: attenuation, dynamic mass, energy dissipation, grip force, vibration, white finger.

Measurements of mechanical impedance in the handarm system have not generally shown close agreement $(1,2,3,5)$. Undoubtedly some of the differences have been due to experimental techniques, as well as to factors such as different postures and grips adopted by the subject. The object of the present study was to perform repeated measurements on a limited number of subjects in order to assess the accuracy with which impedance in the hand-arm system might be determined. It was not the intention to investigate the effect which different experimental variables such as grip force and posture had on the impedance, but rather to choose a particular experimental technique and establish the degree of reliability which could be associated with this specific method of measurement.

\section{Method}

Two adult male subjects were used, and the impedance in their hand-arm systems was measured at 28 frequencies between 10 and $800 \mathrm{~Hz}$. Measurements of the magnitudes of force and acceleration and the phase difference between them were made on a 2-cm diameter handle which was held with a constant grip force of about $20 \mathrm{~N}$. Figure 1 shows the experimental arrangement. The subject's arm was maintained in a horizontal position with the elbow bent, and the force and acceleration in the vertical, ie, $\mathrm{X}$, direction were read off the appropriate root-mean-square (rms) meters. Each subject was tested six times at each of the 28 frequencies. The experiment was repeated when the subjects were wearing an inflatable air-cushion glove. It is believed that this glove had been manufactured

\footnotetext{
'Department of Applied Acoustics, University of Salford, Salford M5 4WT, England.
}

Reprint requests to: Dr TI Hempstock, Department of Applied Acoustics, University of Salford, Salford M5 4WT, England. as a device which would reduce the transmission of vibration to the hand.

Measurements on the handle alone revealed that it behaved as a perfect mass with the force remaining in phase with the acceleration over the frequency range investigated. When the handle was gripped, the ratio of force to acceleration measured on the handle gave the dynamic mass of the hand plus handle. Subtraction of the real and imaginary parts of the impedance in the handle from that in the handle + hand gave the impedance in the hand for each subject.

Repeating the experiment when the subject was wearing the glove enabled the impedance in the hand + glove combination to be determined.

\section{Results and discussion}

As each subject was tested six times, the standard error of the mean value of each determination of the dynamic mass could be estimated. These standard errors are reflected in figures 2 and 3 , where the magni-

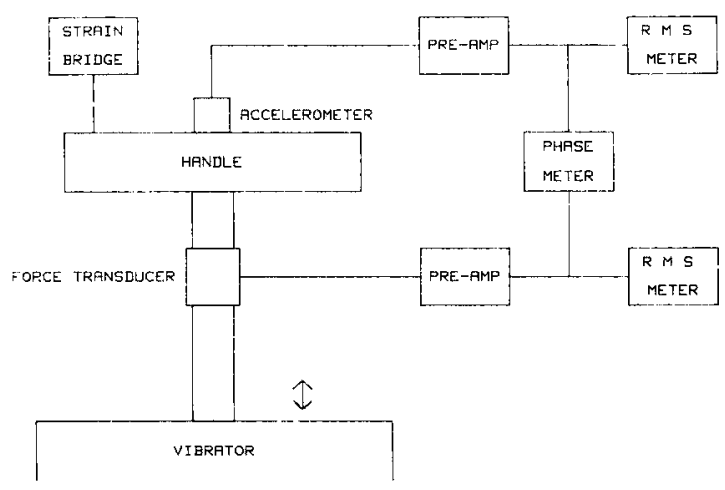

Figure 1. Experimental arrangement used for making the measurements. (RMS = root-mean-square) 


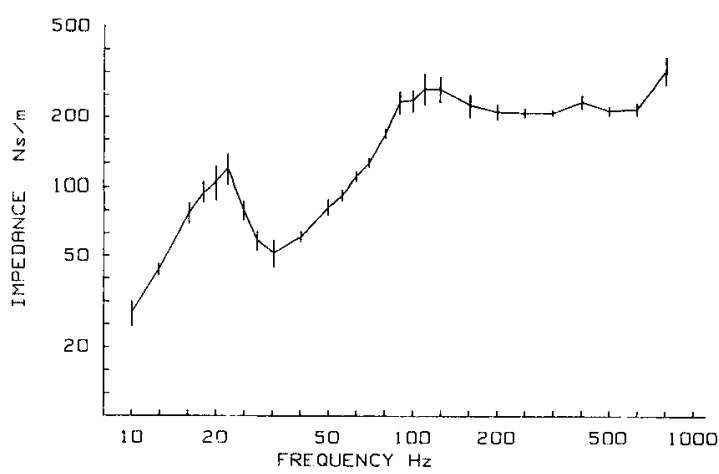

Figure 2. Magnitude of impedance measured in the hand-arm system in the $X$ direction plus and minus one standard error - Subject 1 .

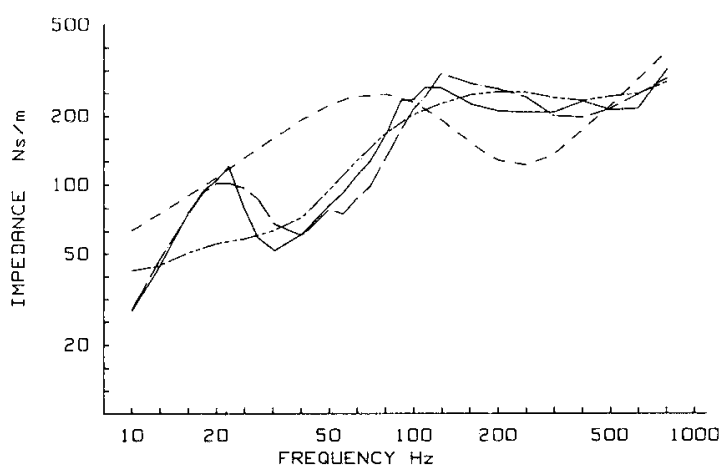

Figure 4. Comparison of measured and proposed model values of hand-arm impedance in the $X$ direction. (- subject 1 , -...- subject 2, _......- Reynolds \& Falkenberg (2), - - - model of the International Organization for Standardization)

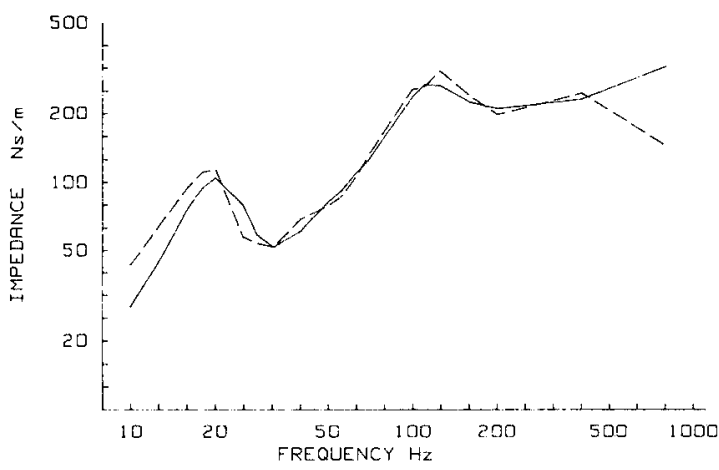

Figure 6. Effect of wearing an air cushion glove on the magnitude of impedance in the hand-arm system - Subject 1. ( 1 without glove, --- with glove)

tudes of impedance (ie, dynamic mass $\times 2 \pi \mathrm{f}$ ), together with the associated standard errors, are shown for each subject at each of the 28 frequencies tested. The highest of these standard errors was about $25 \%$, but generally they were of the order of $10 \%$ with a tendency towards even smaller values at higher frequencies. Within a range of \pm 2 standard errors the results from the two subjects overlap.

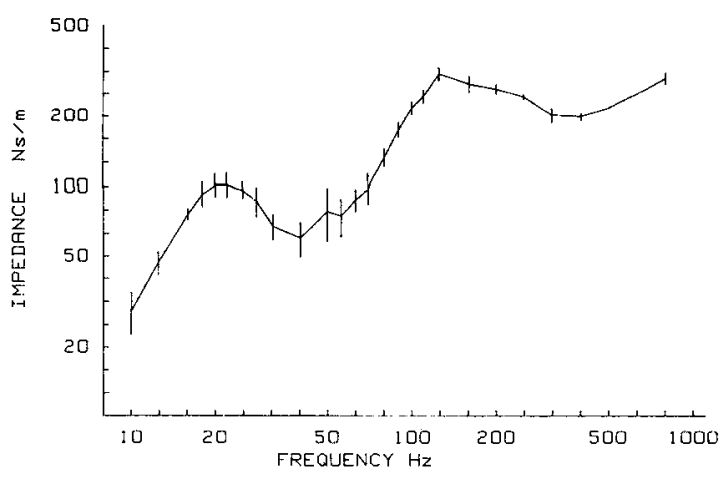

Figure 3. Magnitude of impedance measured in the hand-arm system in the $X$ direction plus and minus one standard error - Subject 2 .

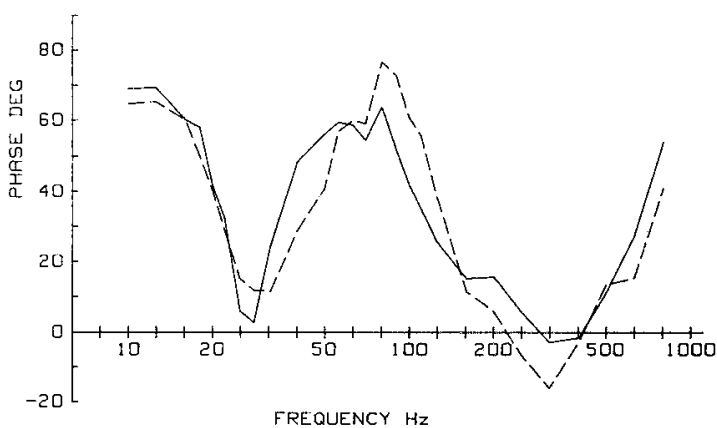

Figure 5. Phase of impedance in the hand-arm system in the $X$ direction for both subject $1(\longrightarrow)$ and subject $2(----)$. (DEG = degrees)

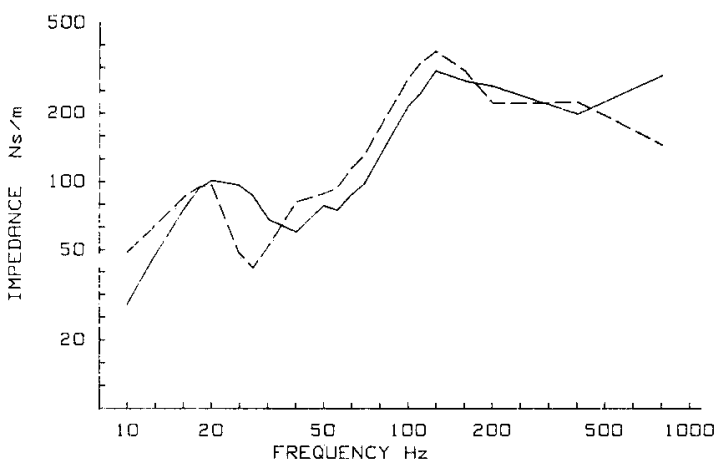

Figure 7. Effest of wearing an air cushion glove on the magnitude of impedance in the hand-arm system - Subject 2. without glove, _.. with glove)

Figure 4 shows the magnitude of the impedance for each subject and compares these magnitudes with the results of another recent study by Reynolds \& Falkenberg (2). Also shown in the diagram is the curve which has recently been circulated within the International Organization for Standardization (ISO) as an initial proposal for an international standard of impedance in the hand-arm system. It is clear that at frequencies 


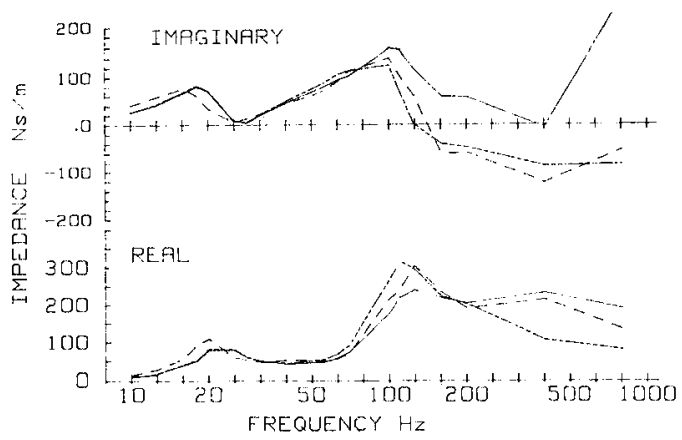

Figure 8. Real and imaginary parts of hand-arm impedance measured and computed for subject 1 . (_._. without glove; _ _ _ with glove; _...... with glove, computed using

model)

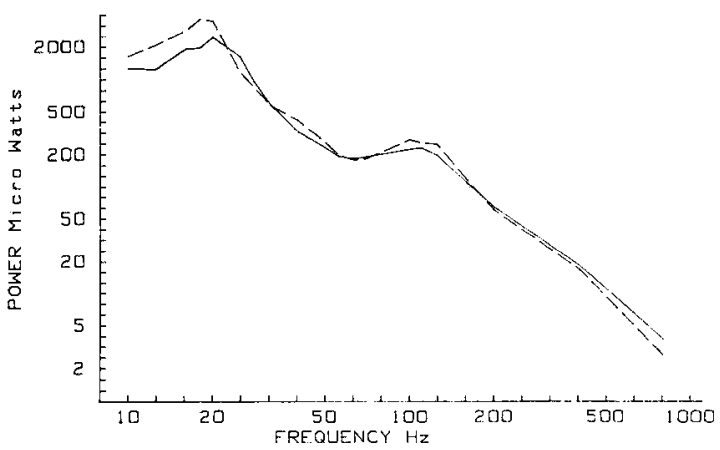

Figure 10. Power dissipated with (- - ) and without ( the wearing of gloves - Subject 1 .

above about $25 \mathrm{~Hz}$ the three sets of measured values agree quite well. The reason for the discrepancy below $25 \mathrm{~Hz}$ is not clear. The principal difference in the experimental procedure was that, whereas the present study used a fixed frequency technique, Reynolds \& Falkenberg (2) used a technique which involved a continuous sweep of frequency from 5 to $1000 \mathrm{~Hz}$. A doubt is therefore raised as to whether the measurement of impedance when the frequency is changing is necessarily a valid measure.

Although the magnitudes of the "within subject" standard deviations indicate close agreement between the impedances for the two subjects used, it is possible that measurements on a larger sample would give rise to a larger "between subject" standard deviation. Thus the differences in impedance shown in figure 4 may well be less significant if a larger population were used. Nevertheless, it is important that any measurement technique should be known to be reliable and capable of achieving an acceptable degree of accuracy.

The ISO model shows some significant variation from both sets of measured data.

Figure 5 shows the calculated phase differences between the force and velocity for each subject. It clearly indicates the two resonances which occur and also shows close agreement between the two subjects.

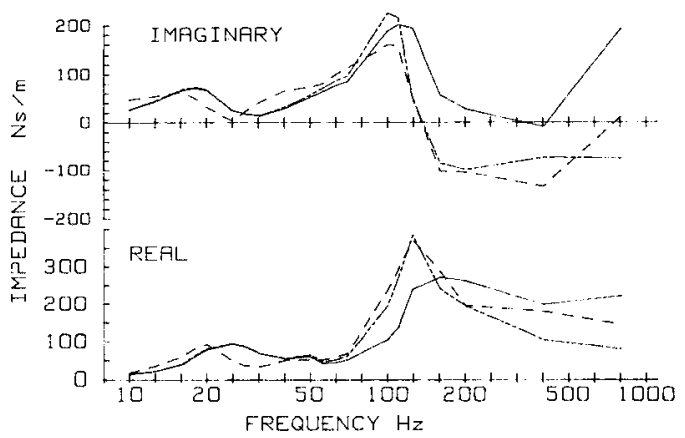

Figure 9. Real and imaginary parts of impedance measured in the hand-arm system and computed for subject 2 . (without glove; --
puted using model)

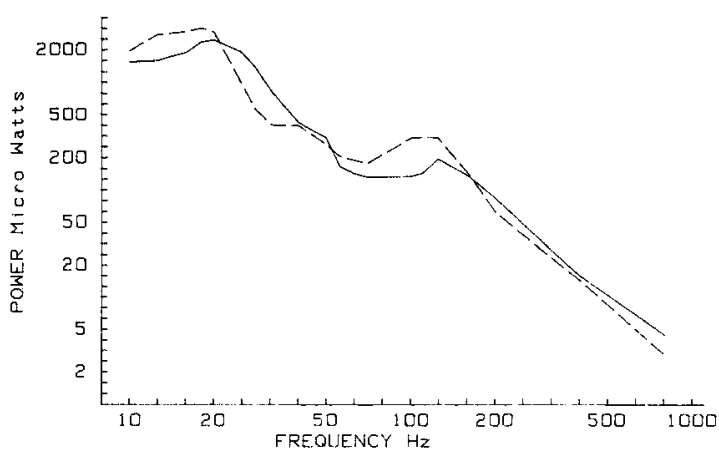

Figure 11. Power dissipated with (- - ) and without (the wearing of gloves - Subject 2 .

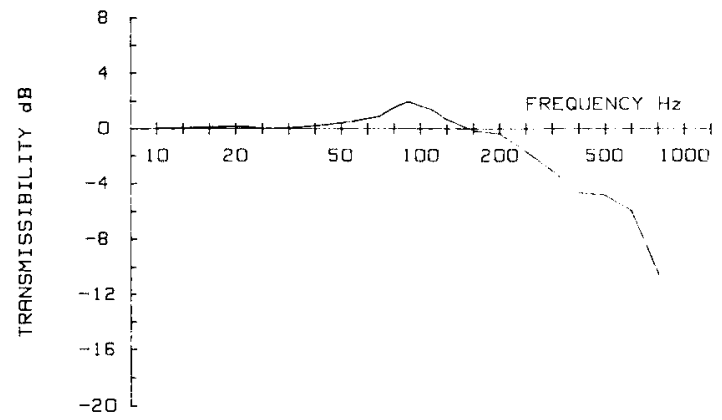

Figure 12. Estimated transmissibility of the air cushion glove.

When the experiment was repeated with the subjects wearing the glove, small changes occurred. Figures 6 and 7 show the magnitudes of the impedances for each subject with and without the gloves being worn. It appears that with standard errors of the sizes reported earlier, it is not possible to conclude that the wearing of the glove has any significant effect on impedance in the hand-arm system. However if the real and imaginary parts of the two sets of impedance are derived, some changes are apparent at frequencies 
above about $150 \mathrm{~Hz}$. These differences are shown in figures 8 and 9 for each of the two subjects.

\section{Interpretation of the results}

Figures 8 and 9 also show the results of an attempt to fit a simple model of the glove to the data. It is possible to assume a model for the glove which consists of a mass connected by a spring and damper, in parallel, to the hand and then attempt to choose the parameters of the model so that the combination of the impedance of the model, together with that measured for the hand, gives an impedance for the hand + glove combination close to the value which had been determined experimentally. The curves shown in figures 8 and 9 appear to represent the closest degree of fit that could be attained with this simple model, and they are associated with a mass of $0.015 \mathrm{~kg}$, a stiffness constant of $4.5 \times 10^{5} \mathrm{~N} / \mathrm{m}$, and a damping constant of $50 \mathrm{Nsm}^{-1}$.

The measured mass of the glove was $0.06 \mathrm{~kg}$.

The energy dissipated in the hand-arm system can be determined from (4):

$$
\mathrm{W}=\frac{\mathrm{Z} \operatorname{Cos} \phi}{2 \omega^{2}}
$$

where $\mathrm{W}=$ power dissipated for unit constant acceleration input, $Z=$ the magnitude of impedance in the hand-arm system, and $\phi=$ the phase difference between the force and the velocity.

The magnitude of this quantity is shown for each subject with and without the glove being worn in figures 10 and 11 . Clearly the use of the glove makes little difference to the value of the total power dissipated at any frequency between 10 and $800 \mathrm{~Hz}$. In an attempt to assess the transmissibility of the glove, the velocity at the hand-glove interface was calculated, and hence the ratio of the velocities at the hand-glove interface and at the handle was determined. The results of this calculation for one subject are shown in figure 12. Clearly the glove provides little attenuation at any except the highest of frequencies and would appear to be of minimal value as a device for the prevention of vibration-induced white finger.

\section{Conclusions}

1. Measurements repeated six times on two subjects only made it possible to determine the magnitude of impedance in the hand-arm system to within an accuracy of about $10 \%$.

2. The impedances were in close agreement with those of another study at frequencies above about $25 \mathrm{~Hz}$, but they differed from the model proposed by ISO.

3. The use of an air cushion glove had little effect on impedance in the hand and also caused little change in the total energy dissipated.

4. An attempt at fitting a simple model to represent the glove and hence calculating its attenuation suggested that the glove would provide minimal attenuation of vibration and therefore offer little protection against vibration-induced white finger.

\section{References}

1. Diekmann D. Ein mechanisches modell fur das schwengungerregte hand-arm system des menschen. Int $Z$ Angew Physiol einschl. Arbeitsphysiol 17 (1957) 125.

2. Reynolds DD, Falkenberg RJ. Three- and four-degreesof-freedom models of the vibration response of the human hand. In: Brammer AJ, Taylor W, ed. Vibration effects on the hand and arm in industry. John Wiley \& Sons, New York, NY 1982, pp 117-132.

3. Reynolds DD, Soedel W. Dynamic response of the hand arm system to a sinusoidal input. J Sound Vib 21 (1972): $3,339-353$.

4. Reynolds DD, Wasserman DE, Basel R, Taylor W. Energy entering the hands of operators of pneumatic tools used in chipping and grinding operations. In: Brammer AJ, Taylor W, ed. Vibration effects on the hand and arm in industry. John Wiley \& Sons, New York, NY 1982, pp $133-146$.

5. Suggs CW, Mishoe JW. Hand-arm vibration: Implications drawn from lumped parameter models. In: Wasserman DE, Taylor W, Curry MG, ed. Proceedings of the international occupational hand-arm vibration conference. National Institute for Occupational Safety and Health, Cincinnati, OH 1977, pp 136-141. (DHEW publication no $77-170$ ). 